\title{
Peripheral Oxidation Markers in Down Syndrome Patients: The Better and the Worse
}

\author{
Dominik Szwajgier (D), Ewa Baranowska-Wójcik (D), ${ }^{1}$ Joanna Grzelczyk, ${ }^{2}$ \\ and Wioletta Żukiewicz-Sobczak ${ }^{3}$ \\ ${ }^{1}$ Department of Biotechnology, Microbiology and Human Nutrition, University of Life Sciences in Lublin, Skromna 8, \\ 20-704 Lublin, Poland \\ ${ }^{2}$ Institute of Food Technology and Analysis, Faculty of Biotechnology and Food Sciences, tódź University of Technology, \\ 90-924 Łódź, Poland \\ ${ }^{3}$ Department of Food and Nutrition, Calisia University, Nowy Świat 4, 62-800 Kalisz, Poland
}

Correspondence should be addressed to Dominik Szwajgier; dominik.szwajgier@up.lublin.pl

Received 21 January 2021; Revised 26 May 2021; Accepted 15 June 2021; Published 29 June 2021

Academic Editor: Helge Frieling

Copyright (c) 2021 Dominik Szwajgier et al. This is an open access article distributed under the Creative Commons Attribution License, which permits unrestricted use, distribution, and reproduction in any medium, provided the original work is properly cited.

Oxidative stress plays an important role in Down syndrome (DS) pathology since the gene dose effect leads to abnormal levels of certain enzymes and metabolites. In this review, we focused on relatively easy-to-obtain, peripheral markers of oxidative stress and inflammation, in order to compare the levels of these markers in DS patients and chromosomally healthy persons. Studies taking into account age- and sex-matched control groups were of particular interest in this context. We analyzed the factors that influence the levels of said markers in both groups (i.e., the usefulness of the markers), including the age of DS patients, occurrence of regular trisomy 21 or mosaicism, physical activity of patients, and the onset of Alzheimer's disease in DS. This paper was conceived as a handbook-to help for selecting suitable, easy-to-obtain markers for monitoring of the health status of DS patients (e.g., in nutritional studies and during dietary supplementation).

\section{Introduction}

As discussed by Roizen and Patterson (2003), the overexpression of at least 330 genes, since encoded by the chromosome 21 , can play a part in the DS, including 16 genes involved in the mitochondrial energy production, 10 genes with a structural and functional role in the CNS, and 6 genes involved in folate metabolism. The authors underlined some mitochondrial abnormalities in DS patients, which lead to dysfunctions in mitochondrial energy production and metabolism of ROS [1]. Therefore, the cells of a DS patient are permanently subject to inflammation and excessive oxidation incidents which continue throughout their life (Figure 1).

The genetic and physiological mechanisms underlying the origin of ROS overproduction and oxidative stress in DS have been very thoroughly discussed in a number of papers, e.g., in a work of Busciglio and Yankner [2] and the excellent reviews by Barone et al. [3] or Valenti [4].
The presented review, however, does not focus on brain and cerebrospinal fluid oxidation markers as our aim was to identify comparatively easy-to-obtain sources of analytic material. For example, mitochondrial membrane potential $(\Delta \Psi)$ and mitochondrial ultrastructure are affected by excessive oxidation in DS, but the prevalent method of measuring is complex and not really useful in daily clinical practice. Similarly, some sources of samples (fetal brain, brain, amniotic fluid) are difficult to use in human patients on a regular basis. The use of cerebrospinal fluid is not very suitable due to the invasiveness and potential risks of postlumbar puncture headaches. The search for sources of reliable oxidation markers in long-term studies of persons with DS should be focused on sources such as saliva, urine, and blood, where sample collection is relatively simple, noninvasive, and causes little anxiety in patients.

The system of cellular enzymatic antioxidants (SOD, GPx, CAT, and GR) in DS has been discussed in many papers, e.g., in the excellent review by Pagano and Castello 


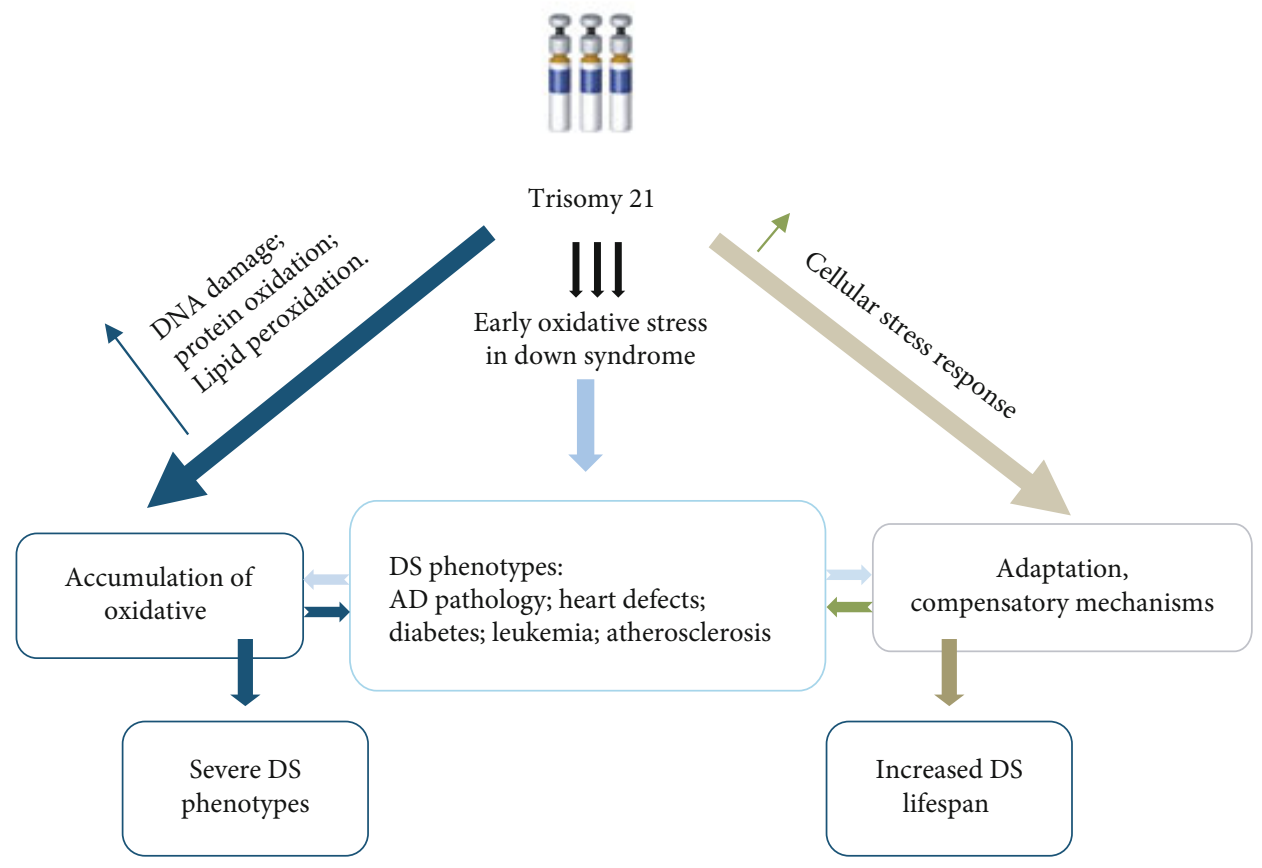

FIGURE 1: Putative adaptation to oxidative stress in DS. Accumulation of oxidative damage leads to severe phenotypes while the induction of compensatory mechanisms in response to chronic oxidative stress could result in "adaptation" and could contribute to improve the life span of DS subjects.

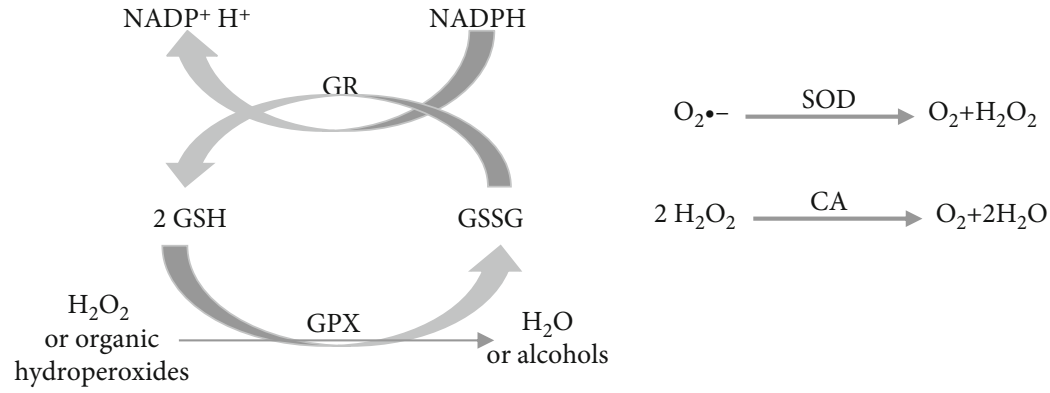

Figure 2: Antioxidant enzymes. CAT: catalase; GPX: glutathione peroxidase; GR: glutathione reductase; $\mathrm{H}_{2} \mathrm{O}_{2}:$ hydrogen peroxide; $\mathrm{O}_{2} \cdot{ }^{-}$: superoxide; SOD: superoxide dismutase.

(2012) (Figure 2) [5]. Excessive oxidative stress is caused by elevated levels of $\mathrm{Cu} / \mathrm{Zn}$ SOD (SOD1) which is coded for on chromosome 21, region 21q22-1, and in DS SOD1 which is overexpressed by approximately $50 \%$ relative to control, non-DS patients [6], thus playing an important role in DS-related oxidative stress [7, 8]. As presented in the Supplementary Table 1, most authors reported on the increased GPx activity in DS patients, but some papers evidenced opposite results [9] or similar GPx levels in DS and corresponding matched control groups [10] (Supplementary Table 1).

TAA is a general indicator of the antioxidant status in vivo. However, the difference in TAA in DS and non-DS patients can be interesting, instead of values in individual studies. Moreover, comparisons between individual reports are difficult due to the use of various analytical methods applied for the measurement of TAA. Most papers report decreased TAA in samples taken from DS patients, in com- parison with non-DS counterparts [11-14] (Table 1). Some studies, however, show that TAA in DS patients was increased, in comparison with healthy controls [15], or no difference was observed [16-18] (Table 1).

Some general information about the status of DS patients may be obtained by monitoring the products of lipid and protein oxidation. TBARS is another possible marker of oxidation. However, conflicting results concerning DS patients were obtained by authors who observed increased [19] as well decreased [20] TBARS levels, whereas in other works, no significant differences in serum lipid peroxides or TBARS were reported [10, 21-23]. MDA can be considered a convenient marker in DS. Authors reported on increased levels of MDA in urine, erythrocytes, plasma, or peripheral blood [9, 24-27] (Supplementary Table 2).

In the past, the level of thiol (sulfhydryl) groups was measured in patients, including those with DS. Glutathione (in various forms) is one of the most important sulfur 


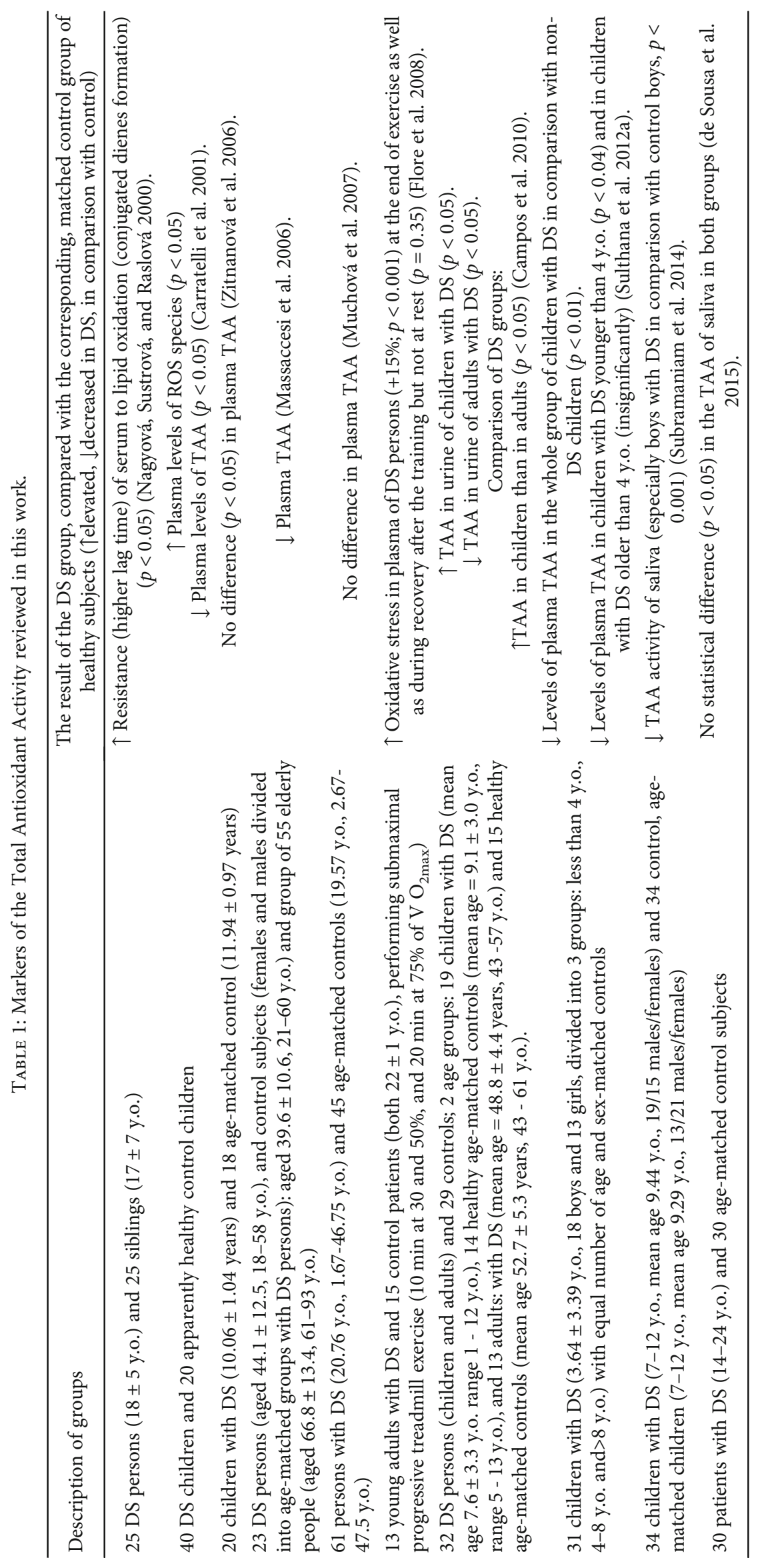




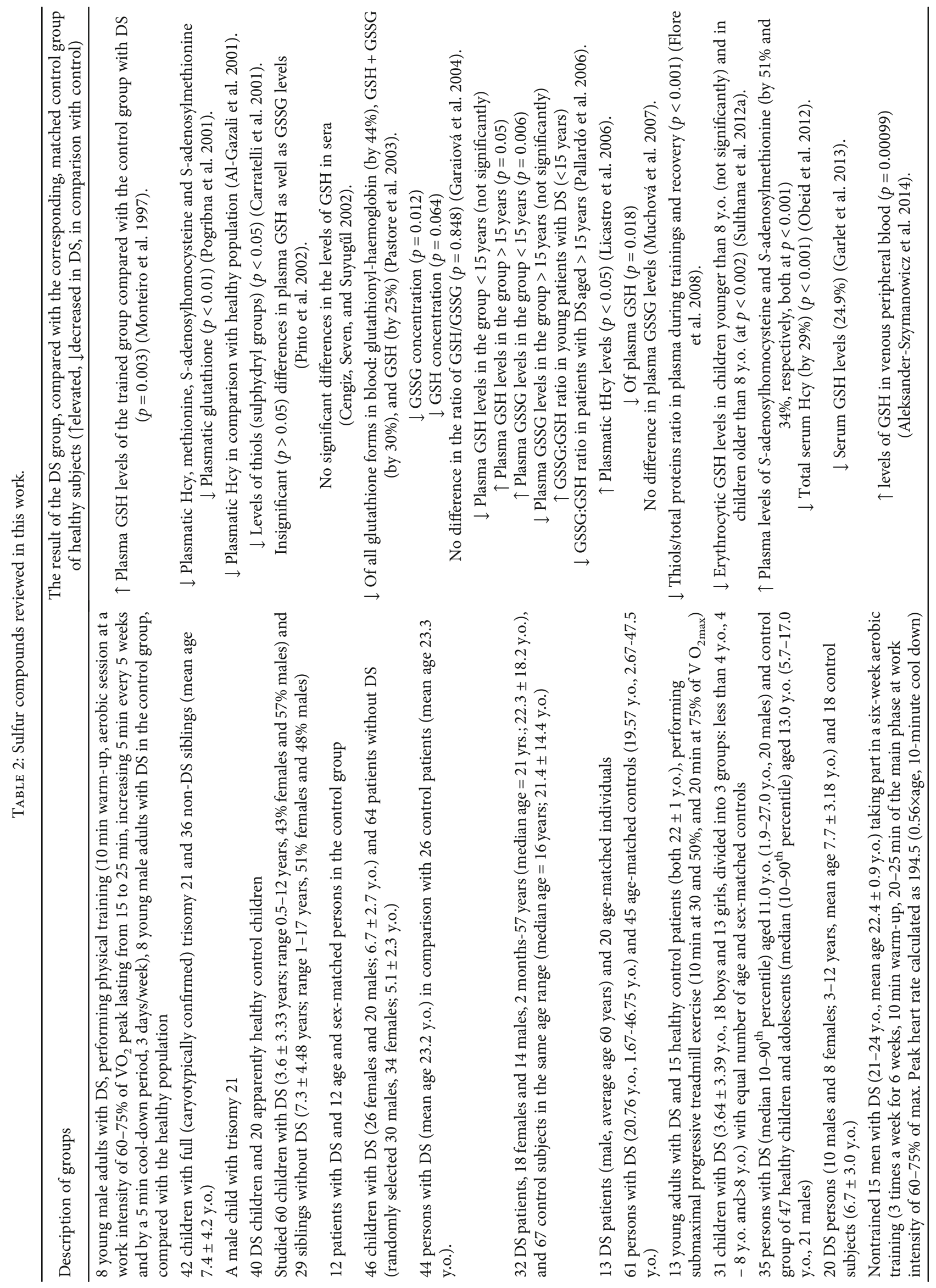




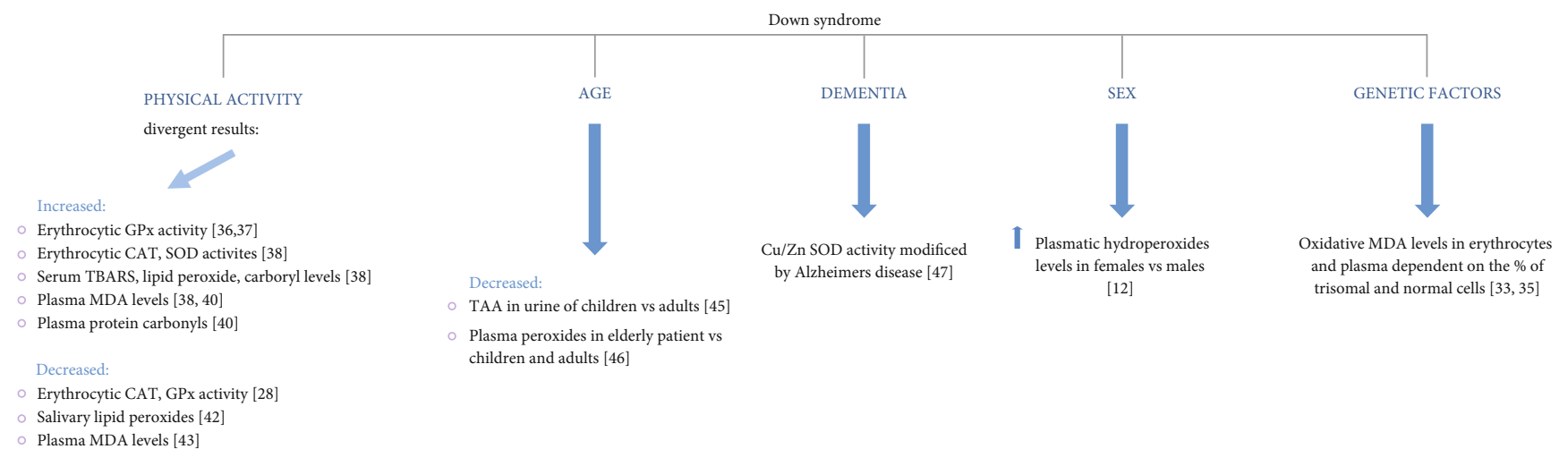

FIgURE 3: The most significant factors that affect the levels of markers in DS.

compounds reflecting the antioxidant status in vivo. In numerous works, plasmatic glutathione was decreased in DS patients compared to their healthy counterparts $[10,13$, $28,29]$. However, some authors showed insignificant differences in plasma glutathione levels, in comparison with healthy patients $[30,31]$ (Table 2).

\section{Factors That Can Affect the Levels of Markers in DS}

Some independent factors may influence the outcome of experiments involving a comparison between DS patients and healthy individuals. First of all, genetic factors should be taken under consideration. $\mathrm{Cu} / \mathrm{Zn} \mathrm{SOD}, \mathrm{CAT}, \mathrm{GPx}$ GR, and MDA levels in DS patients with translocations between chromosomes 14-21, 21-21, and 10-21 were similar to those of age-matched individuals with regular trisomy. The greater the percentage of the normal cell line was present in patients, the lower the oxidative stress observed [32]. De la Torre et al. (1996) reported increased SOD activity in erythrocytes in a population of DS patients with complete trisomy 21 but not in karyotyped persons (by $42 \%$ and $28 \%$, respectively). At the same time, the authors observed normal SOD activity in the population with partial trisomy 21 , translocations, and mosaicism [33]. MDA levels were dependent on the percentage of diploid and trisomy cells, and Casado, López-Fernández, and Ruiz (2007) observed increased MDA levels in persons with DS as compared to Robertsonian translocation trisomy. Therefore, serum, plasma, or erythrocytic MDA levels seem to be a suitable marker of the oxidative status in DS patients, with the reservation that in the case of DS persons with mosaicism, MDA levels are dependent on the percentage of diploid and trisomy cells (Casado, LópezFernández, and Ruiz 2007) [34].

Physical activity strongly affects the outcome of experiments, as shown in numerous works. It was shown that GPx activity in erythrocytes was significantly elevated after physical training relative to the basal level in DS persons $[35,36]$. Erythrocytic (but not serum) SOD activity and erythrocytic and serum CAT activity were increased (in both cases at $p=0.05$ ) in the DS group due the physical activity. Moreover, significantly increased TBARs, serum lipid peroxides, and protein carbonyls levels (both at $p=0.05$ ) were reported [37]. However, in another study, erythrocytic SOD and GPx activity was significantly decreased after physical training [27]. Increased oxidative stress in the plasma of DS patients after physical training has been reported, including increased MDA and decreased thiol/total proteins ratio in the plasma in the DS group subjects, in comparison with the basal levels registered for the same persons prior the training [38, 39]. The observed levels of plasma carbonyl proteins after the training program in the DS group were increased in comparison with the baseline (the same DS patients before the training, $p=0.001)$. Also, no significant differences in this parameter were reported in healthy controls at the end of the training, compared with baseline (healthy controls before training, $p>0.05$ ) [39]. However, certain authors have presented contradictory results. Monteiro et al. (1997) reported on the elevated levels of plasma GSH $(p=0.003)$ in the trained group of patients with DS as compared to the control group of DS subjects not taking part in the training [40]. Zambrano et al. (2009) showed that aerobic exercise caused a significant decrease in the levels of salivary lipid hydroperoxides in the DS group $(p=0.001)$, but had no impact on TAA and nitrite levels [41]. Ordonez and Rosety-Rodriguez (2006) observed reduced plasmatic MDA levels (at the end of the physical training, compared to initial levels) [42]. Aleksander-Szymanowicz et al. (2014) reported on increased GSH levels in venous peripheral blood of adult men with DS after physical training [43].

The age of the patients should also be taken into account when considering the levels of oxidation markers. Campos et al. (2010) observed increased TAA levels in the urine of children with DS $(p<0.05)$ and decreased TAA in the urine of adults with DS $(p<0.05)$, compared to matched, healthy groups. TAA in DS children was increased $(p<0.05)$ as compared to TAA of DS adults [44]. Muchová et al. (2001) reported on significant differences in plasma MDA concentrations in erythrocytes between individuals with DS aged 13-20 years and those over 20 years old $(p=0.05)$ [18]. Licastro et al. (2007) reported decreased levels of plasma peroxides in elderly patients as compared to children and adults with DS (both at $p<0.05$ ) [45].

In a number of works, dementia or sex was identified as independent factors. Percy et al. (1990) reported on the differences in the increase of erythrocytic $\mathrm{Cu} / \mathrm{Zn}$ SOD activity in DS patients with and without AD [46]. Massaccesi et al. (2006) showed that plasmatic hydroperoxide levels in 
females with DS were higher than in the case of males with DS $(p<0.05)$ [12]. The most significant independent factors that affect the levels of markers in DS are summerized in Figure 3.

\section{Conclusions}

In this paper, we provided a considerable number of oxidation/inflammation markers discriminating DS from the diploid state and created a useful tool (handbook) to be used while planning new nutritional experiments. MDA can be considered a convenient marker in DS, as generally agreed by authors. TAA, TBARS, or sulphur levels in DS patients cannot be a reliable marker of oxidation in DS due to the conflicting results found in the original papers cited in this review. Further studies concerning the usability of said selected markers are highly recommendable.

Monitoring of the levels of oxidation markers should account for selected factors interrupting the levels measured in DS patients, mainly the specific type of DS, age, and physical activity of the patient.

To reconcile the conflicting results reported by the authors cited above, a prospective study on a group of DS patients can be proposed in order to measure the marker at the beginning of the supplementation and at the end of the experiment. For example, a precisely planned experiment focused on the effects of antioxidant supplementation on oxidative stress in DS patients should be conducted to examine a larger number of markers. Parisotto et al. (2014) studied the activity of SOD, CAT, GPx, GR, GST, $\gamma$-glutamyltransferase, and glucose-6-phosphate dehydrogenase, as well as the levels of GSH, UA, TBARS, and protein carbonyls in the peripheral blood of 21 DS patients (3-14 y.o., $7.7 \pm 3.18$ y., 12 males, and 9 females) and 18 control children (10 males and 8 females; $3-12$ y.o., $6.7 \pm 3.0$ years), before and after daily antioxidant administration over a period of 6 months (vitamin C $500 \mathrm{mg}$, E $400 \mathrm{mg}$ ) [47]. Before the antioxidant therapy, erythrocytic SOD and CAT activity was elevated in DS relative to the control group (by $47 \%$ and $24.7 \%$, respectively). Also, GR and $\gamma$-glutamyltransferase activity was significantly increased (by $98 \%$ and $97 \%$, respectively) in DS persons compared to the controls. After supplementation, the erythrocytic GST activity in DS subjects was decreased (61\%) compared to the controls. The whole blood concentration of GSH in DS patients was reduced by $27 \%$. The levels of UA in DS persons were higher (by 19\%) than in the control. No significant difference between TBARS levels in DS and the control group was observed before supplementation. At the basal state, protein carbonyls were decreased (by 40\%) in the DS group relative to the controls. After the 6-month antioxidant supplementation, there was a significant decrease in the GR and $\gamma$-glutamyltransferase (37\%) activity in the supplemented group. The GST erythrocytic activity in DS subjects was significantly increased (44\%). After 6 months of antioxidant supplementation, the previously depleted GSH levels (by 27\%) were restored. UA levels were unaffected by the antioxidant supplementation but a significant decrease in TBARS (by 181\%) was observed in the supplemented DS group. Last but not least, supplementation had no effect on the levels of protein carbonyls in either the DS or the control group [47]. In another work, the same authors monitored biomarkers of inflammation in the peripheral blood of 21 DS patients and 18 children (IL- $1 \beta$ and TNF- $\alpha$, TBARS, protein carbonyls, GSH, and UA levels as well as SOD, CAT, GPx, GR, and GST activity) [48]. The authors designed a prospective study involving antioxidant supplementation for 6 months followed by testing, 6 months of interruption, and retesting, followed by antioxidant supplementation for another 6 months and the final retesting.

Following this experimental scheme, the evolution in the levels of oxidation/inflammation markers as well as in the activity of endogenous antioxidants can be continuously monitored in order to verify the effects of the supplementation therapy.

\section{Abbreviations}

ABTS: $\quad 2,2^{\prime}$-azino diethylbenzothiazo-line sulfonic acid

AD: Alzheimer's disease

CAT: Catalase

CNS: Central nervous system

CRP: C-reactive protein

DS: Down syndrome

GPx: Glutathione peroxidase

GR: Glutathione reductase

GSH: Reduced glutathione

GS-Hb: Glutathionyl-hemoglobin

GSSG: Oxidized glutathione

GST: Glutathione S-transferase

Hb: Hemoglobin

Hcy: Homocysteine

oxLDL: Oxidized low density lipoprotein

MDA: Malondialdehyde

ROS: Reactive oxygen species

SOD: Superoxide dismutase

TAA: Total antioxidant activity

TBARS: Thiobarbituric acid reactive substances

tHcy: Total homocysteine

UA: Uric acid

VLDL: Very low-density lipoproteins.

\section{Data Availability}

Not applicable-it is a review.

\section{Conflicts of Interest}

The authors declare no conflict of interest.

\section{Authors' Contributions}

DS performed the conceptualization; resources; data curation; writing - original draft preparation, review, and editing; and supervision. B-W.E. contributed to the resources, writing-original draft preparation, and visualization. G.J. performed the writing-original draft preparation. Z-S.W. performed the formal analysis, writing-original draft, and funding. 


\section{Acknowledgments}

This study was supported from the resources of the Ministry of the Higher Education of the Republic of Poland.

\section{Supplementary Materials}

Supplementary Table 1: endogenous enzymes reviewed in this work. Supplementary Table 2: lipid and protein oxidation products reviewed in this work. (Supplementary Materials)

\section{References}

[1] N. J. Roizen and D. Patterson, "Down's syndrome," The Lancet, vol. 361, no. 9365, pp. 1281-1289, 2003.

[2] J. Busciglio and B. A. Yankner, "Apoptosis and increased generation of reactive oxygen species in Down's syndrome neurons in vitro," Nature, vol. 378, no. 6559, pp. 776-779, 1995.

[3] E. Barone, A. Arena, E. Head, A. D. Butterfield, and M. Perluigi, "Disturbance of redox homeostasis in down syndrome: role of iron dysmetabolism," Free Radical Biology and Medicine, vol. 114, pp. 84-93, 2018.

[4] D. Valenti, N. Braidy, D. de Rasmo et al., "Mitochondria as pharmacological targets in Down syndrome," Free Radical Biology and Medicine, vol. 114, pp. 69-83, 2018.

[5] G. Pagano and G. Castello, "Oxidative stress and mitochondrial dysfunction in Down syndrome," in Neurodegenerative Diseases. Advances in Experimental Medicine and Biology, pp. 291-299, Springer, New York (NY), 1st edition, 2012.

[6] G. Annerén and B. Edman, "Down syndrome- a gene dosage disease caused by trisomy of genes within a small segment of the long arm of chromosome 21 , exemplified by the study of the effects from the superoxide type-1 (SOD-1) gene," APMIS Supplementum, vol. 40, pp. 71-79, 1993.

[7] K. Brugge, S. Nichols, T. Saitoh, and D. Trauner, "Correlations of glutathione peroxidase activity with memory impairment in adults with Down syndrome," Biological Psychiatry, vol. 46, no. 12, pp. 1682-1689, 1999.

[8] P. Zis, M. Dickinson, S. Shende, Z. Walker, and A. Strydom, "Oxidative stress and memory decline in adults with Down syndrome: longitudinal study," Journal of Alzheimer's Disease, vol. 31, no. 2, pp. 277-283, 2012.

[9] J. He, T. Li, J. Chen et al., "Plasma antioxidant enzymes and lipoperoxidation status in children with down syndrome," Clinical Biochemistry, vol. 49, no. 1-2, pp. 61-65, 2016.

[10] T. R. Garlet, E. B. Parisotto, G. . S. de Medeiros et al., "Systemic oxidative stress in children and teenagers with Down syndrome," Life Sciences, vol. 93, no. 16, pp. 558-563, 2013.

[11] M. Carratelli, L. Porcaro, M. Ruscica, E. De Simone, A. A. Bertelli, and M. M. Corsi, "Reactive oxygen metabolites and prooxidant status in children with Down's syndrome," International Journal of Clinical Pharmacology Research, vol. 21, pp. 79-84, 2001.

[12] L. Massaccesi, M. M. Corsi, C. J. Baquero-Herrera et al., "Erythrocyte glycohydrolases in subjects with trisomy 21: could Down's syndrome be a model of accelerated ageing?," Mechanisms of Ageing and Development, vol. 127, no. 4, pp. 324-331, 2006.

[13] S. M. Sulthana, S. N. Kumar, M. G. Sridhar, B. V. Bhat, and K. R. Rao, "Levels of non enzymatic antioxidants in Down syn- drome," The Indian Journal of Pediatrics, vol. 79, no. 11, pp. 1473-1476, 2012.

[14] P. Subramaniam, K. L. Girish Babu, and L. Mohan Das, "Assessment of salivary total antioxidant levels and oral health status in children with Down syndrome," Special Care in Dentistry., vol. 34, no. 4, pp. 193-200, 2014.

[15] A. Nagyova, M. Sustrova, and K. Raslova, "Serum lipid resistance to oxidation and uric acid levels in subjects with Down's syndrome," Physiological Research, vol. 49, pp. 227-231, 2000.

[16] I. Zitnanová, P. Korytár, H. Sobotová et al., "Markers of oxidative stress in children with Down syndrome," Clinical Chemistry and Laboratory Medicine, vol. 44, no. 3, pp. 306-310, 2006.

[17] M. C. de Sousa, R. B. Vieira, D. S. dos Santos et al., "Antioxidants and biomarkers of oxidative damage in the saliva of patients with Down's syndrome," Archives of Oral Biology, vol. 60, no. 4, pp. 600-605, 2015.

[18] J. Muchová, M. Šustrová, I. Garaiová et al., “Influence of age on activities of antioxidant enzymes and lipid peroxidation products in erythrocytes and neutrophils of down syndrome patients," Free Radical Biology and Medicine, vol. 31, no. 4, pp. 499-508, 2001.

[19] M. E. Garcez, W. Peres, and M. Salvador, "Oxidative stress and hematologic and biochemical parameters in individuals with Down syndrome," Mayo Clinic Proceedings, vol. 80, no. 12, pp. 1607-1611, 2005.

[20] M. Ferreira, R. Rodrigues, E. Motta et al., "Evaluation of extracellular adenine nucleotides hydrolysis in platelets and biomarkers of oxidative stress in Down syndrome individuals," Biomedicine \& Pharmacotherapy, vol. 74, pp. 200-205, 2015.

[21] G. Capone, P. Kim, S. Jovanovich et al., "Evidence for increased mitochondrial superoxide production in down syndrome," Life Sciences., vol. 70, no. 24, pp. 2885-2895, 2002.

[22] C. Campos, R. Guzmán, E. López-Fernández, and A. Casado, "Evaluation of urinary biomarkers of oxidative/nitrosative stress in children with Down syndrome," Life Sciences, vol. 89, no. 17-18, pp. 655-661, 2011.

[23] C. Campos, R. Guzmán, E. López-Fernández, and A. Casado, "Evaluation of urinary biomarkers of oxidative/nitrosative stress in adolescents and adults with down syndrome," Biochimica et Biophysica Acta (BBA)-Molecular Basis of Disease, vol. 1812, no. 7, pp. 760-768, 2011.

[24] S. V. Jovanovic, D. Clements, and K. MacLeod, "Biomarkers of oxidative stress are significantly elevated in Down syndrome," Free Radical Biology \& Medicine, vol. 25, no. 9, pp. 1044-1048, 1998.

[25] I. Garaiová, J. Muchová, M. Šustrová et al., “The relationship between antioxidant system and some markers of oxidative stress in persons with Down syndrome," Biologia, vol. 596, pp. 787-794, 2004.

[26] S. M. Sulthana, S. N. Kumar, M. G. Sridhar, B. V. Bhat, and K. R. Rao, "Oxidative stress in children with Down syndrome," Current Pediatric Research, vol. 16, pp. 111-114, 2012.

[27] U. Ozbey, C. Arslan, Y. Savucu, A. Seyran, and M. Erisir, "Oxidative stress and altered levels of antioxidants in adolescents with down syndrome during pre-exercise and post-exercise," African Journal of Microbiology Research, vol. 6, no. 27, pp. 5625-5630, 2012.

[28] M. Pogribna, S. Melnyk, I. Pogribny, A. Chango, P. Yi, and S. J. James, "Homocysteine metabolism in children with Down syndrome: in vitro modulation," The American Journal of Human Genetics, vol. 69, no. 1, pp. 88-95, 2001. 
[29] A. Pastore, G. Tozzi, L. M. Gaeta et al., "Glutathione metabolism and antioxidant enzymes in children with Down syndrome," The Journal of Pediatrics, vol. 142, no. 5, pp. 583585, 2003.

[30] M. Pinto, J. Neves, M. Palha, and M. Bicho, "Oxidative stress in Portuguese children with Down syndrome," Down's Syndrome, Research and Practice, vol. 8, no. 2, pp. 79-82, 2002.

[31] M. Cengiz, M. Seven, and N. Suyugül, "Antioxidant system in Down syndrome: a possible role in cataractogenesis," Genetic Counseling, vol. 13, no. 3, pp. 339-342, 2002.

[32] Á. Casado, M. E. López-Fernández, and R. Ruíz, "Oxidative stress markers in down syndrome," International Medical Review on Down Syndrome, vol. 9, pp. 18-25, 2005.

[33] R. De la Torre, A. Casado, E. López-Fernández, D. Carrascosa, V. Ramírez, and J. Sáez, "Overexpression of copper-zinc superoxide dismutase in trisomy 21," Experientia, vol. 52, no. 9, pp. 871-873, 1996.

[34] A. Casado, M. E. López-Fernández, and R. Ruiz, "Lipid peroxidation in down syndrome caused by regular trisomy 21 , trisomy 21 by Robertsonian translocation and mosaic trisomy 21," Clinical Chemistry and Laboratory Medicine, vol. 45, no. 1, pp. 59-62, 2007.

[35] O. Francisco Javier, R. Manuel, and R. R. Manuel, "Regular physical activity increases glutathione peroxidase activity in adolescents with Down syndrome," Clinical Journal of Sport Medicine, vol. 16, no. 4, pp. 355-356, 2006.

[36] N. A. Meguid, A. M. Eltohamy, M. Anwar, A. F. Hashish, and A. Elnahry, "Efficacy of selected treadmill training program on oxidative stress in adolescents with Down syndrome," Eastern Mediterranean Health Journal, vol. 19, pp. 131-137, 2013.

[37] A. S. Aguiar Jr., T. Tuon, M. M. Albuquerque et al., "The exercise redox paradigm in the Down's syndrome: improvements in motor function and increases in blood oxidative status in young adults," Journal of Neural Transmission, vol. 115, no. 12, pp. 1643-1650, 2008.

[38] P. Flore, V. A. Bricout, D. van Biesen et al., "Oxidative stress and metabolism at rest and during exercise in persons with Down syndrome," European Journal of Cardiovascular Prevention \& Rehabilitation, vol. 15, no. 1, pp. 35-42, 2008.

[39] F. J. Ordonez, I. Rosety, M. A. Rosety et al., “Aerobic training at moderate intensity reduced protein oxidation in adolescents with Down syndrome," Scandinavian Journal of Medicine \& Science in Sports, vol. 22, no. 1, pp. 91-94, 2012.

[40] C. P. Monteiro, A. Varela, M. Pinto et al., "Effect of an aerobic training on magnesium, trace elements and antioxidant systems in a Down syndrome population," Magnesium Research, vol. 10, no. 1, pp. 65-71, 1997.

[41] J. C. Zambrano, R. Marquina, N. Sulbarán, A. J. RodríguezMalaver, and R. A. Reyes, "Aerobic exercise reduced oxidative stress in saliva of persons with Down syndrome," Research in Sports Medicine, vol. 17, no. 3, pp. 195-203, 2009.

[42] F. J. Ordonez and M. R. Rosety-Rodriguez, "Regular exercise attenuated lipid peroxidation in adolescents with Down's syndrome," Clinical Biochemistry, vol. 40, pp. 141-142, 2006.

[43] P. Aleksander-Szymanowicz, A. Marchewka, Z. Dabrowski, A. Teleglow, A. Bac, and J. Glodzik, "The influence of moderate-intensity physical effort on peripheral blood in adults with Down syndrome - a pilot study," Journal of Physiology and Pharmacology, vol. 65, no. 5, pp. 733-738, 2014.

[44] C. Campos, R. Guzmán, E. López-Fernández, and A. Casado, "Urinary uric acid and antioxidant capacity in children and adults with Down syndrome," Clinical Biochemistry, vol. 43, no. 3, pp. 228-233, 2010.

[45] F. Licastro, G. Dogliotti, G. Goi, A. E. Malavazos, M. Chiappelli, and M. M. Corsi, "Oxidated low-density lipoproteins (oxLDL) and peroxides in plasma of Down syndrome patients," Archives of Gerontology and Geriatrics, vol. 44, pp. 225-232, 2007.

[46] M. E. Percy, A. J. Dalton, V. D. Markovic et al., "Red cell superoxide dismutase, glutathione peroxidase and catalase in Down syndrome patients with and without manifestations of Alzheimer disease," American Journal of Medical Genetics, vol. 35, no. 4, pp. 459-467, 1990.

[47] E. B. Parisotto, T. R. Garlet, V. L. Cavalli et al., "Antioxidant intervention attenuates oxidative stress in children and teenagers with Down syndrome," Research in Developmental Disabilities, vol. 35, no. 6, pp. 1228-1236, 2014.

[48] E. B. Parisotto, A. G. Giaretta, A. Zamoner et al., "Persistence of the benefit of an antioxidant therapy in children and teenagers with Down syndrome," Research in Developmental Disabilities, vol. 45-46, pp. 14-20, 2015.

[49] J. Nève, P. M. Sinet, L. Molle, and A. Nicole, "Selenium, zinc and copper in Down's syndrome (trisomy 21): blood levels and relations with glutathione peroxidase and superoxide dismutase," Clinica Chimica Acta, vol. 133, no. 2, pp. 209-214, 1983.

[50] J. Kędziora, G. Bartosz, J. Gromadzińska, M. Skłodowska, W. Wȩsowicz, and J. Scianowski, "Lipid peroxides in blood plasma and enzymatic antioxidative defence of erythrocytes in Down's syndrome," Clinica Chimica Acta, vol. 154, no. 3, pp. 191-194, 1986.

[51] M. C. Pastor, C. Sierra, M. Doladé et al., "Antioxidant enzymes and fatty acid status in erythrocytes of Down's syndrome patients," Clinical Chemistry, vol. 44, no. 5, pp. 924-929, 1998.

[52] F. J. Ordonez, M. Rosety-Plaza, and M. Rosety-Rodriguez, "Glucose-6-phosphate-dehydrogenase is also increased in erythrocytes from adolescents with Down syndrome," Down Syndrome Research and Practice, vol. 11, no. 2, pp. 84-87, 2006.

[53] F. J. Ordonez, M. Rosety, and M. Rosety-Rodriguez, "Regular exercise did not modify sig-nificantly superoxide dismutase activity in adolescents with Down's syndrome," British Journal of Sports Medicine, vol. 40, no. 8, pp. 717718, 2006.

[54] J. Muchová, I. Garaiová, M. Šustrová et al., "The redox state of glutathione in erythrocytes of individuals with Down syndrome," Brastisl. Med. J, vol. 108, pp. 70-74, 2007.

[55] O. Akinci, E. Mihci, S. Tacoy, F. Kardelen, I. Keser, and M. Aslan, "Neutrophil oxidative metabolism in Down syndrome patients with congenital heart defects," Environmental and Molecular Mutagenesis, vol. 51, no. 1, pp. 57-63, 2010.

[56] G. Goi, C. Baquero-Herrera, F. Licastro, G. Dogliotti, and M. M. Corsi, “Advanced oxidation protein products (AOPP) and high-sensitive C-reactive protein (hs-CRP) in an "atheroma-free model": Down's syndrome," International Journal of Cardiology, vol. 113, no. 3, pp. 427-429, 2006.

[57] L. I. Al-Gazali, R. Padmanabhan, S. Melnyk et al., "Abnormal folate metabolism and genetic polymorphism of the folate pathway in a child with Down syndrome and neural tube defect," Am. J. Med.Genet., vol. 103, no. 2, pp. 128-132, 2001. 
[58] F. V. Pallardó, P. Degan, M. d'Ischia et al., "Multiple evidence for an early age pro-oxidant state in Down syndrome patients," Biogerontology, vol. 7, no. 4, pp. 211-220, 2006.

[59] F. Licastro, A. Marocchi, S. Penco et al., "Does Down's syndrome support the homocysteine theory of atherogenesis?: Experience in elderly subjects with trisomy 21," Archives of Gerontology and Geriatrics, vol. 43, no. 3, pp. 381-387, 2006.

[60] R. Obeid, K. Hartmuth, W. Herrmann et al., "Blood biomarkers of methylation in down syndrome and metabolic simulations using a mathematical model," Molecular Nutrition \& Food Research, vol. 56, no. 10, pp. 1582-1589, 2012. 